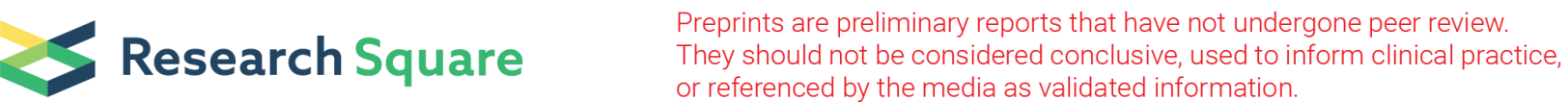

\section{The Limits of Free Health Care Schemes: the Case of Access to Care for Beneficiaries of the Moroccan Medical Assistance Scheme (RAMed) Suffering From Cancer}

\section{Jean-Noël Ferrié ( $\boldsymbol{\sim}$ jean-noel.ferrie@uir.ac.ma )}

International University of Rabat: School of Political Sciences https://orcid.org/0000-0001-5890-297X

\section{Mohammed Ababou}

Sidi Mohamed Ben Abdellah University: Faculty of Letters and Human sciences

\section{Wassila Benkirane}

Sidi Mohamed Ben Abdellah University: Faculty of Letters and Human sciences

\section{Zineb Omary}

International University of Rabat:School of Political sciences

\section{Saadia Radi}

Université Internationale de Rabat: Universite Internationale de Rabat

\section{Research}

Keywords: Free health cares, Access to care, Targeted policies, Structural policies, Cancer, Morocco

Posted Date: September 15th, 2021

DOl: https://doi.org/10.21203/rs.3.rs-875705/v1

License: (c) (1) This work is licensed under a Creative Commons Attribution 4.0 International License.

Read Full License 


\section{Abstract}

Background: The article discusses the limitations of a free-of-charge scheme for the poor in the case of cancer patients. The literature on free access to hospitals, especially on the African continent, has already mentioned these limits: occasional payments for care and transport. The particularly ambitious Moroccan free-of-charge scheme (RAMEd) presents the same problems

Methods: It is based on a qualitative survey of 120 patients and 30 doctors or nurses with whom we conducted semi-structured interviews over several months.

Results: The results show that patients continue to pay for care and medical imaging as well as their transport to the hospital. They pay for care and examinations that are not available at the hospital or wait for them to be available, which is a danger to their chances of survival.

Conclusions: The limitation of the RAMed is that it does not cover the cost of transport or the structural deficiencies of the hospital. The result is the paradox of a free service that is costly for patients. We stress that targeted policies cannot replace structural policies and, on their own, do not remedy inequalities, particularly territorial inequalities.

\section{Introduction}

Patient fee exemption schemes have three objectives: (1) a public health objective, (2) an objective of combating inequalities, and, more broadly, (3) an objective of establishing or strengthening social protection. The literature on this subject, particularly in Africa - both in North Africa and in Sub-Saharan Africa - is important, as are the debates linked to it. If free health care can, from the patients' point of view, be undeniably considered as an improvement, in that it ensures at least a better access to health care, its limits appear numerous, even if the engineering of the systems is judicious and based on inventive approaches. In fact, the focus on the intrinsic quality of the cost recovery systems and the hope placed in their regenerative capacities lead their designers to underestimate their dependence on the context, and in particular on the overall state of the health system. The result is a hybrid situation, combining improved access to care with an increase in dysfunctional situations. The latter can be understood more easily from the point of view of the beneficiaries of these schemes, whose therapeutic itineraries clearly reveal the inadequacies of the health systems and the inability of the free schemes to compensate for them. On the contrary, they make them more visible.

We will address this question based on field surveys conducted between 2018 and 2019, in Morocco, in the cities of Fez, Meknes and Khenifra, on access to care for people with cancer and benefiting from the Medical Assistance Scheme (RAMed). These results were consolidated with other results from an older survey (2016), conducted by our team on access to care for RAMed beneficiaries.

\subsection{The debate on free access in Africa}


Free access to health care has been the subject of much debate and focus [1, 2] on Africa, and in particular on sub-Saharan Africa $[3,4,5,6,7]$. The main criticism of free access is its economic sustainability. However, it is difficult to imagine, as things stand, the effective implementation of complete and unconditional free access, just as it was - in the wake of the Bamako Initiative - difficult to envisage the pure and simple introduction of generalized payment [8]. In practice, free health care is selective in terms of categories and baskets of care as well as the targeted population. Like all public policies, it does not escape politicization and the complementary mechanisms of seeking legitimacy [9] and avoiding blame [10] on the part of the political actors who decide on them and supervise their implementation. Some free education projects, such as the Sesame Plan in Senegal [11], are thus clearly part of the search for legitimacy and appear to be connected to electoral issues [12]. In addition to the general questioning of the sustainability of free education, there is a specific questioning, not without foundation, of the conditions and contexts of its implementation. Not all contexts lend themselves to it in the same way. In fact, beyond the implementation of free health care systems, a global reform of the health care system appears to be necessary in order to allow (1) effectively cost-free access for patients to (2) quality care, which also implies the coverage of transport, the elimination of informal and indirect costs, etc. [2]. From this point of view, it is undeniable that free care is meaningless if it is not accompanied by a real and effective financial effort in favor of the care system and its environment [13].

\subsection{The Medical Assistance Plan (RAMed)}

The Medical Assistance Plan (RAMed) is a free care scheme in the public health system. It is manifested by an exemption of payment for the patients who benefit from it. The basket of care is particularly wide. This system was envisaged and partially designed in the 1990s, which were pivotal years in the country's contemporary development. First, the country was emerging from the Structural Adjustment Plan (19831990), which had a negative impact on the development of social infrastructure. Second, it entered a phase of political openness. This took two forms: (a) the promotion of a broad conception of human rights that will gradually broaden to include human development; (b) the formation of a consensus on institutions, including all political parties, within the framework of an increasing liberalization of the regime [14]. Third, the development of social policies, which will be placed at the heart of the objectives of King Mohammed VI's reign. The Universal Medical Insurance (AMU) and the Medical Assistance Scheme (RAMed) were initiated under the "Government of Alternation" (1998-2002). This government was led by a former political opponent and leader of the Moroccan socialist party (Union socialiste des forces populaires). It marks the return of left-wing parties to the Moroccan political game.

The RAMed was carefully prepared, mobilizing the technical expertise of specialists from various ministries between 1998 and 2002. The law establishing the Medical Assistance Scheme was passed in 2002; however, the implementing decree was not issued until 2008. This was followed by a two-year experimental period in the Tadla-Azilal region. The decree of generalization of RAMed was signed on January 24, 2011. Various adjustments to the system were, however, added during 2011 and required a decree. The effective generalization took place more than a year after the regulatory generalization, on March 13, 2012. The whole process therefore took twelve years. Barely four years after this 
generalization, the RAMed had more than ten million affiliated persons, including 6,345,525 with active rights [15]. However, as early as 2014 the public authorities began to worry about the sustainability of the scheme. Evaluations were initiated, including one conducted by the National Observatory of Human Development (ONDH).

Several questions arose. (1) The first concerned the number of beneficiaries. Initially, it had been planned that they would be divided into non-contributory "poor" and contributory "vulnerable" (with a ceiling of 600 DH per household). The project designers had estimated that $65 \%$ would be contributors. After the implementation of RAMed, they represented only $16 \%$ of the population covered while, during the same period, the High Commission for Planning (HCP) counted, in 2014, 1,605,000 poor people (in terms of relative poverty). The criteria used to be considered "poor" by the RAMed were thus much more inclusive than those used by the HCP, which seems to be due primarily to the targeting instruments used [16]. This resulted in strong pressure from the demand for free care on a hospital system that was already considered insufficiently equipped at the time of the generalization of RAMed [17]. (2) The second issue was the financing of the system. None of the financial modalities planned to support the scheme had been implemented; they still are not [18]. Free care is currently financed by the ordinary operating budget of hospitals, whereas it was planned that the care provided would be invoiced and the bills paid by the State according to a mechanism to be put in place. (3) The state of the health infrastructure and its capacity to accommodate RAMed beneficiaries. As indicated in the report on the sectoral strategy of the Ministry of Health for the period 2012-2016 [17], the health infrastructure at the time of the launch of RAMed was already insufficient, since at the time when the Moroccan government was beginning to worry about RAMed's sustainability, the share of the State budget devoted to it was 5.6\% (2014), whereas the share recommended by the WHO was $9 \%$.

\subsection{Overall impact on beneficiaries}

In addition to these strictly financial issues, there is also the question of the impact of the scheme on its beneficiaries $[19,20,21]$. The first scientific publications point to a number of problems, this even highlighted by Yates: the continuation of patient payments and the difficulties related to their transportation from their places of residence to the care structure. A survey of 186 hemodialysis beneficiaries of RAMed in the Souss-Massa region highlighted these difficulties: lack of medical transport and ambulances to take patients from their homes to the hemodialysis center; payment of at least part of the medical analyses, as hemodialysis patients have to resort to private imaging and medical analysis centers to make up for the shortcomings of the public sector. To meet these expenses, patients are forced to go into debt [21]. This pathology-related situation is confirmed, from a general point of view, by a study based on the analysis of 2013 and 2015 data from the Moroccan Household Survey Panel Data (MHSPD) of the National Observatory of Human Development (ONDH). It shows that the expenditures of households benefiting from RAMed are equivalent to those of comparable households not benefiting from RAMed [20]. In other words, the effects of the disease on household impoverishment are equivalent; however, they are not equivalent in terms of the effects on health, since the main part of the care is covered by the RAMed, and from this point of view, populations suffering from serious pathologies have 
effective access to the care they need (as shown by the case of dialysis patients). The result is that, while the public health objective seems to be substantially being achieved, the objective of combating inequalities is marking time and the overall well-being of patients remains limited.

\section{Method And Approach}

The choice of a qualitative approach, involving semi-structured interviews, stems from the fact that it is necessary to enter into the daily life of people in order to evaluate the moral and financial costs of a care system. At this stage, we cannot operate from above the beneficiaries of the system. This information bias stems from a general tendency, present in the evaluation of public policies, to underestimate the practical and ordinary consequences of these policies [22]. The paradox, as Anne Revillard [23] strongly emphasizes, is that evaluation bypasses the consequences on individuals in order to focus on the performance of public action, yet this performance is only a means to an end; and it is in relation to the end - the impact on the lives of everyone - that a public policy must be evaluated.

\subsection{Description of the survey}

We conducted a qualitative survey using semi-structured interviews, involving patients $(N=120)$ and health care personnel $(\mathrm{N}=30)$, notably doctors and nurses. We did not distinguish between forms of cancer, as we were interested in the difficulties of access for patients. Certainly, difficulties or facilities inherent to particular forms of cancer appeared, but this point remains secondary in our survey. A little more than two thirds $(68 \%)$ of the patients we interviewed came from or resided in rural areas. This was due to the cities we had chosen: Khenifra, the capital of a rural province in the Middle Atlas, Meknes and Fez, which receive patients from the surrounding rural areas, especially Khenifra. This over-representation of rural people was deliberate, since our research focused on identifying and assessing access difficulties. In both Khenifra and Meknes, our surveys were conducted with patients from a provincial hospital; in Fez, it was a University Hospital Center (CHU).

Most of the interviews were conducted in situ, in the oncology centers of Meknes and Fez. This allowed us to observe at the same time the daily routine of the care facilities, the arrival of patients, their care, interactions and, sometimes, altercations with the caregivers. The interviews generally lasted between half an hour and an hour. They were conducted either in Moroccan dialect Arabic (Darija) or in French, especially with the doctors and head nurses. The interviews we conducted focused on access to care. To do so, we asked patients to describe the steps they have taken and are taking to remedy their ailments, from the symptoms or incentives (e.g., prevention campaigns) that led them to seek care to the sequence of diagnosis and care. The survey was authorized by the Ethics Committee of the Faculty of Medicine of Fez and supported by the Moroccan Cancer Research Institute (IRC).

In addition, we use, in this article, some interviews conducted at the Hassan II University Hospital Center (CHU) in Fez on the occasion of an between survey conducted in 2015, concerning access to care for RAMed beneficiaries. The more general framework of the care sectors considered allows us to better 
situate the difficulties encountered by cancer patients. This survey was authorized by the Ethics Committee of the Faculty of Medicine of Rabat and financed by the National Observatory of Human Development (ONDH) as part of an evaluation program of RAMed.

\section{Results Of The Survey}

Our survey showed that the initiation of patients' ${ }^{\dagger}$ therapeutic itineraries did not concern the main course of care, generally surgery (if necessary) and chemotherapy, but sometimes radiotherapy, examinations and, more broadly, the phases preceding this main course or following it. Examinations are generally problematic, in the sense that their availability is not guaranteed. These problems are all the more present when dealing with care structures far from the university hospital, as shown in the interview below:

"Until now, we have been able to have free chemo sessions, scans and certain analyses, but we have to go elsewhere when the analyses do not exist here. We had problems when she had complications in the brain, these analyses cost $2000 \mathrm{DH}^{\ddagger}$, and they did not exist in the hospital, neither in Sidi Said nor in Mohamed V. So we were obliged to take an appointment here, at the CHU, we had an appointment for one month (...)

- So, what are the things that your mother has been paying for all along?

- Doctor's fees, biopsy, MRI, ECG, chemo tests, injections at $100 \mathrm{DH}$, and treatment after chemo.

- And the analyses for the ganglion, did she also pay for them?

- Yes, the biopsy at Moulay Ismail Hospital, but the analysis at the private laboratory at $600 \mathrm{DH}$. »§

In addition to these problems of availability of medical services, there are problems of transport, as patients have to travel from their homes to the place of care or examination. Depending on the circumstances, transportation problems also involve accommodation problems, if patients are received as outpatients but cannot be cared for on the day of their arrival. In general, however, patients note the advantages of the RAMed and consider quite unanimously that "without it, [they would] not have been able to be treated". Nevertheless, their journeys are marked by payments and these are linked to deficiencies affecting the place of care to which they belong.

\subsection{The unavailability of care}

The notion of deficiency appears to be important for qualifying the unavailability of care. Under the terms of the law instituting the RAMed, as well as from the point of view of the organization of the health system, not all care and not all examinations are and need to be available in each medical facility. Some require the presence of a category of care or examination, others do not. We considered unavailability to be a deficiency when the care or test was supposed to be available but was not. The interviews conducted with medical and nursing staff were very useful in that they gave us an overview of the care and examinations available and supposed to be available in the various institutions. 
In fact, the medical pathways appear to be riddled with deficiencies:

"People in Oujda [the respondent lives in Oudja] do the chemotherapy sessions, but when they want to do the radiotherapy, they have to go to the clinic and there they have to have a lot of money.

- And what did you do?

- We came to Fez where they refused to give him radiotherapy and then to Rabat where we were told that radiotherapy was available in Oujda. In Oujda, they gave us a technical form (sic) to get rid of us. When we showed the form to Fez and Rabat, the people in charge of the department told us that we should not come here at all.

- And?

- Did we go to a private clinic?

- How much did it cost you?

- $9000 \mathrm{DH}$ for a session plus $900 \mathrm{DH}$ for the scanner, he needed 3 or 4 sessions.

- So in total?

- around 3 million [DH cents].

- And for MRI,

- We were given an appointment for two months from now but we did it in private the same day. We gave him a $500 \mathrm{DH}$ injection.

(..)

- When she found out she was sick, did she have the RAMed card?

- Yes, she already had it.

- So thank God.

- Yes, of course, you know the people who don't have RAMed in Oujda do the same treatments and they pay $600 \mathrm{DH}$ per session; some have to do 30 sessions.

- $600 \mathrm{DH}$ the session at the clinic?

- No $600 \mathrm{DH}$ at the public hospital but in a clinic it costs $1500 \mathrm{DH}$.

- So at first you paid for the MRI, 
- Yes $300 \mathrm{DH}$.

- And the analyses? How much is it?

- The biopsy at $500 \mathrm{DH}$ and the first analyses at $300 \mathrm{DH}$.

- So we loaned you the money for the MRI,

- Yes... $3000 \mathrm{DH}$

- And to get here? Transportation costs?

- Someone else loaned us the money.

- How many kilometers is that?

-300 kms.

- How long does it take?

- Three hours by car and five hours by bus.

- And by train?

- The train is too expensive.

- How much does a round trip cost?

- She must always be accompanied because of her health condition.

- Are you the one who always comes with her?

- Yes, it's still me and I have to leave my little girl in Oujda.

- This time who came with her?

- This time there is his sister and me.

- How much did it cost you?

- It is $100 \mathrm{DH}$ the place in bus, that is to say $600 \mathrm{DH}$ for a round trip.

- Were you asked for money (bribery) to get the RAMed card?

- Not at all.

(..) 
- Has your budget been affected by the disease?

- Yes, a lot, when we want to make purchases we give up because we prefer to keep the money for the expenses of the illness.

- And morally?

- It has changed our lives.

- When you arrive in Fez at the bus station, how do you get to the hospital?

- By cab (20 DH) and also a cab when we want to go from our home to Oujda to the bus station.

- What about fatigue?

- Yes, a lot especially since she is sick. » ${ }^{*}$

This case is quite long. The therapeutic itinerary began with radiotherapy, which was not available in Oujda, where the patient lived, so she moved to Fez and then to Rabat, in order not to have to leave the public system where she benefited from RAMed coverage of her care. The patient was finally treated in Fez, at the Oncology Center of the University Hospital. She therefore travels from Oujda to Fez for her radiotherapy sessions, covering more than 300 kilometers. This trip is the consequence of a deficiency, since radiotherapy should be available in Oujda. The cost of transport and accommodation is doubled, since the patient is accompanied by her daughter. It should also be noted that the MRI was performed in the private system, in order to avoid the two-month waiting period indicated to the patient. This was due to the large number of people who needed to undergo this examination and the lack of available machines. However, the question of delays does not only concern the examinations. It can be a more global issue for the entire medical care, as shown in the case below. The patient was sent by a clinic to the University Hospital of Fez after it diagnosed a brain cancer requiring surgery that the patient could not handle. He therefore turned to the public system but had to wait several months before he could be operated on. When he was discharged, a CT scan was required, which had to be done in a clinic, again because of the length of the waiting time:

"Who gave him this appointment?

- University Hospital. It was very far away as an appointment, that's the problem. The appointments are very far away.

- Patients cannot bear to wait for these long periods.

- Yes, so when he was admitted to the hospital, he had surgery last November. He was here for 15 days. When he was discharged, he was asked to have a CT scan, we were given a very distant appointment, so we did it at the clinic. " ${ }^{+\dagger}$ 
This situation is reflected in all the interviews we conducted. The long waiting times are a direct consequence of the disproportion between the number of people being cared for and the resources available. In general, we found that all patients, at one time or another, had to leave the medical pathway, either for procedures that were covered but unavailable, or for expenses that were not covered, such as medication (other than those provided as part of hospital care) or transportation to get from their home to the hospital facility. At this point, the patient and family are left to fend for themselves, i.e., to take care of the step that cannot be accomplished within the medical pathway. As the interviews show, these situations are painful. First of all, because they involve choosing to pay not to wait or to pay for access to medication. The patient and his or her family are then forced to make a trade-off between the stress felt, the pain or the risk of loss of life chances, on the one hand, and the expenses required for other essential household needs, on the other. This often results in the use of assistance from close family members (children, parents, siblings) and sometimes more distant ones (cousins). However, these auxiliary resources can only be called upon on an ad hoc basis. As for arbitration, when it is negative, i.e. when the patient cannot make a detour through the private sector in order to benefit from examinations or care not available in the public sector, it implies a risk that can be significant for him or her, as one nurse explains:

"If the patient is developing complications, the examinations allow us to know it, but if we have to wait three months to have the appointment, then carry out the examinations, wait months for a specialized opinion, during this time the pathology evolves and we find ourselves with situations where, because of this delay, complications appear with irreversible consequences. Nothing can be done. We watch helplessly as the patient's condition deteriorates because he is poor. What are you going to do? »

\subsection{The problem of transport}

The problem of transportation appears to be considerable, as patients must, in most cases, travel to the cancer center. There are a dozen public centers in a territory comprising 62 provinces and 12 regions, but there are not as many centers as regions. Rabat (the capital) has 3 structures dedicated to oncology. There are 9 for the rest of the territory. Regardless of whether this is sufficient, the relatively small number of oncology facilities indicates that some of their patients have to travel to receive care. It should be added that, if certain facilities are deficient, patients have to travel to another oncology center than the one to which they belong, and therefore generally to a more distant center. We have thus noted displacements from Oujda to Rabat, Fez and Meknes and displacements from Meknes to Fez. Distance has direct effects on the duration and cost of travel; these effects are all the more important because they are often accompanied by a family member. The two interviews below describe these difficulties:

"What do you use for transportation to get to the cancer center?

- A bus at $40 \mathrm{DH}$ one way.

- How long does the trip take?

-3 hours. 
- Do you go alone or are you accompanied?

- My husband always accompanies me.

- How much does it cost you to go there and back?

- $200 \mathrm{DH}$ approximately, $40 \mathrm{DH}$ multiplied by 4, that is to say $160 \mathrm{DH}$, but the remainder is for the cabs. In any case, when you bring back a blue ticket [a $200 \mathrm{DH}$ ticket], you get it at the end of the day.

- Since the beginning of your illness, how many times have you traveled for treatment?

- I would not know how to answer you, at the beginning I stayed quite often in Meknes, now I move almost every two or three weeks. » $\S$

"Since 5 o'clock in the morning, I am awake, I made the dawn prayer and I came to Meknes from Khenifra. I would have liked to have these treatments in Khenifra without moving, just walking and coming back, but unfortunately I have transportation costs in addition... Once I finish, I return to Khenifra the same day. It costs me $110 \mathrm{DH}$ to make a round trip the same day, not to mention the cabs for $20 \mathrm{DH}$, in Meknes, plus $14 \mathrm{DH}$ of cab in Khénifra, without forgetting the food. For example, I haven't eaten yet, plus I have to eat light, diet, it's even more expensive! (...) It's not only the fatigue on the physical level, because I'm waiting for the moment when I go home myself, but especially the fatigue of asking your relatives for money that weighs heavily on my conscience and affects my dignity. " ${ }^{\star \star \star}$

As can be seen, the problem of transport does not follow on from Thaddeus and Maine's work on the three delays [24], the second delay being that for going from the patient's home to the place of care. In fact, transport is considered in relation to its duration and the urgency of the need for it. Thus, much of the literature on this issue, beginning with Thaddeus and Maine's article, focuses on access to care for childbirth, i.e., the accessibility of care in the event of an emergency. It is not the emergency that prevails in the case of cancer patients. On the other hand, transportation difficulties can lead to irregularities in access to care, and these can be cumulative. In interviews with both health care staff and patients, it appeared that a chemotherapy session could be postponed for three weeks (until the next scheduled session) because the patient could not find or pay for transportation or because the road was not passable (this situation only occurs in winter when there is snow). In some cases, however, the period without care may be longer, when the patient could not find or pay for transportation (first postponement) and then could not leave home because of snow (second postponement). These situations do not appear to be the most numerous, but they do exist. They show that what is at stake in the lack of transport, in the case we are interested in, is not the immediate risk but the long-term risk, the stress and discomfort of the patients as well as their impoverishment. This, however, is not the result of inadequate hospital or RAMed services, but is the result of the lack of a stable, efficient, and robust ambulance and medical transport system in Morocco, and the lack of a system for paying for transport costs. There is therefore not only a problem of access to care, but also a specific problem of access to ambulances [25]. Patients are thus required to pay for their own travel from their homes to hospitals and oncology centers.

Page $11 / 18$ 
t The continuation of the remedies necessary for the treatment of the disease, when they differ from the care pathway provided by the RAMed.

₹ 1 Dirham $(\mathrm{DH})$ is equivalent to a little more or less than 0.09 Euros.

$\S$ Daughter of a 52-year-old patient, Meknes Oncology Center, May 2018.

${ }^{* *}$ Accompanying person (daughter of the patient), 20 years old, $\mathrm{CHU}$ of Fez.

${ }^{+\dagger}$ Accompanying person (daughter of the patient), $\mathrm{CHU}$ of Fez.

\# Nurse, $\mathrm{CHU}$ of Fez.

$\S \S$ Woman, 47 years old, Oncology Center of Meknes.

${ }^{\star \star \star}$ Woman, 39 years old, Oncology Center of Meknes.

\section{Discussion}

What emerges from the field survey that we conducted is the importance of conversions of medical itineraries into therapeutic itineraries, i.e. situations where the different therapeutic phases do not take place within the same care system, because the latter is incomplete. In other words, the RAMed beneficiaries we surveyed, even though they are included in a free access to care system, are still looking for health resources and are obtaining them at their own expense. The same phenomenon can be found in other situations as indicated in the introduction (see above "Introduction"). These are not isolated cases but all the people we met $(\mathrm{N}=120)$. Of course, the payments are of varying importance, but there are always payments: intra-urban and inter-city transport costs, examinations (most often medical imaging), care (radiotherapy, in particular), purchase of medicines, accompaniment costs (for patients who cannot travel alone); and several payments are often combined.

\subsection{Structural problems}

This situation suggests the existence of structural problems, at least two of which seem massive: (1) the organization and management of transport and (2) the availability of the necessary resources in the public system for the completion of the medical pathways for people with cancer. To become aware of these problems, a particular investigation is needed, involving not just looking at the available figures for the increase in hospital care or the continuation of household health expenditure, but at what points in the medical pathway this health expenditure takes place. They could take place upstream of the medical pathway, in a phase of self-medication or independent consultation of private practitioners; they could involve recourse to alternative medicine or result from a voluntary departure from the medical pathway. On the contrary, what appears to be happening is that patients' expenditures are taking place within the stages of the medical pathway, in order to complete them. In other words, patients subsidize the free treatment they receive. 
This state of affairs is general and characterizes access to care for RAMed beneficiaries. However, people with cancer are not ordinary beneficiaries since they are supposed to be part of the National Cancer Prevention and Control Plan (2010-2019) or $\mathrm{NCCP}^{+t+}$, launched in 2010. This plan includes ensuring the provision of care for patients at all levels of the public health system, coordinating them and developing the human resources assigned to these different levels. This plan is supported by the Lalla Salma Foundation ${ }^{\sharp \neq \ddagger}$, wife of King Mohammed Vl, whose action is undeniable [26]. However, this plan does not seem to have a significant impact on the two types of dysfunction that we have mentioned, because they are not so much the result of shortcomings in oncology as of shortcomings in access to care as a whole. Just as the RAMed, as a free-of-charge system, cannot ensure that the necessary resources are present in the health care system, the PNPCC cannot ensure that these resources, which are lacking in general, are present in particular, except possibly in a one-off manner.

In fact, what emerges here is the difficulty of targeted policies. Some resources can only benefit specific categories if they benefit all categories of the population. This is the case for transport infrastructure, including roads, the education system, and the health system. Roads are not built for one type of user but for all users. Similarly, a health system can only take care of a certain category of patients if it is able to take care of all patients. We do not train oncologists, we train doctors first. Thus, when we describe the difficulties of a certain category of patients by following their therapeutic itineraries, we realize that their difficulties are the difficulties of other categories of patients. Looking at things more globally, it appears that the free-of-charge system is not able to guarantee access to all the care involved in the medical pathways, because it is dependent on the state of the hospital system, to which it makes no contribution. Initially, it was planned that the bills of the patients benefiting from free care would be paid by the State, which would have helped to support the hospitals according to their activity. As this mechanism was never put in place, hospitals took over the RAMed from their regular resources, which impoverished them [18]. Indeed, RAMed is not exactly a social security system in that it does not pay for care (and medical transport) where and how it is available (in the public or private sector). It only provides free access to a predefined set of resources (those of the hospital), which it does not help to finance. As a result, cancer patients who are beneficiaries of RAMed find themselves in difficult human and economic situations, even though they are covered by a free-of-charge system. The implementation of a National Cancer Prevention and Control Plan (2010-2019) does not profoundly change the situation in the short or medium term, even if it contributes to an overall improvement in the long term.

\subsection{A holistic perspective}

This situation should lead us to consider the contribution of free health care systems differently: if they are not linked to efforts to develop the health care system, involving an increase in hospital resources and the existence of real out-of-hospital logistics for access to care, they lead to relatively large payments by patients. The question of infrastructure and resources therefore remains central to access to care, as does the question of the share of the state budget devoted to health. From this point of view, the improvement of the situation of a category of patients - in this case those with cancer - is largely 
dependent on the overall improvement of the resources of the health system and the overall development of certain services such as medical transport.

Perhaps a transformation of the paradigm that applies to the management of the social sector and more broadly to state interventions in developing countries is needed. For the sake of efficiency, localized and sectoral solutions seem to be preferred by state or international actors. In fact, it is easier to pursue a circumscribed project of excellence than to reform all the ins and outs of a dysfunction. This is notably the logic of action of NGOs. It is thus simpler and more rewarding to constitute "islands of prosperity and excellence" [27] than to improve entire sectors of public action. However, these islands themselves are dependent on the rest of the sectors to which they are interconnected, and some of what they do continues to depend on them. Holistic perspectives, structural actions, are therefore still needed. In this case, it is clear that the creation of the RAMed has improved access to care for cancer patients, but it has not done more for them than it has for other categories of patients. Similarly, the establishment and conduct of a National Cancer Prevention and Control Plan (2010-2019) has not improved their situation with respect to the two major problems we have indicated: the cost to patients of certain unavailable medical procedures and the cost of transportation. In fact, there seem to be only two solutions to this: (1) increase the resources of the hospital system and set up a real system of medicalized transport or (2) compensate the payments of cancer patients by a specific allowance. This would certainly be a localized but transitory action and above all a compensation and not a public action improvement device. (1) and (2) are complementary. These two solutions are based on two simple principles: the holism of public action (recurrent dysfunctions cannot be resolved without getting to the bottom of things) and the right to compensation when a public service fails to produce the goods it is supposed to produce. The application of these principles has a budgetary cost; their non-application has a human cost. This only underlines an empirical reality which is manifested in other situations of implementation of free access to health care: it is not enough. It depends both on the general conditions of free care delivery, as we have shown, and on the local circumstances of its implementation $[28,29]$. In other words, free care is always limited and variable in scope.

${ }^{+\dagger+}$ see https://www.sante.gov.ma/Documents/Synthese_PNPCC_2010-1019.pdf

\#\# https://www.contrelecancer.ma/fr/

\section{Conclusion}

Our results underline that the success of free health care is largely dependent on the state of the health infrastructure but also on the transport infrastructure and the development of the territory. This question should be developed by also addressing the effect of distance on cancer diagnosis. A study conducted in Morocco on breast cancer showed that diagnosis and treatment were delayed when patients lived more than $100 \mathrm{~km}$ from the place of treatment [30]. This shows that free care is far from sufficient to compensate for territorial inequalities. In fact, it leaves them unchanged. Of course, it increases access to care but inequalities in access remain. In other words, the fight against health inequalities cannot be 
limited to the implementation of free hospital care. Paradoxically, this can increase inequalities, insofar as those who can afford the transport and care or medical imaging that is lacking in the hospital benefit more. This situation creates a great disarray among the beneficiaries.

From a methodological point of view, it seems that the survey by semi-structured interviews is better able to show the importance of this disarray, by showing the place it occupies in the lives of patients and their families. It is not a secondary problem in relation to care. On the contrary, it is about the possibility to benefit from care. When the free care system is not sufficient, the quality of life of patients is directly affected.

\section{Declarations}

\section{Ethical Approval and Consent to participate}

The study was validated by the Ethics Committee of the Faculty of Medicine of Fez Consent for publication

The authors agree to the publication of the article

Availability of supporting data

These are qualitative interviews, several of which are being used for another publication. The data is under embargo until this publication has been published. Thereafter, the interviews will be conditionally available.

Competing interests

Not applicable

\section{Funding}

The research from which this article is derived was supported by the Institute of Cancer Research in Morocco - IRC (REDDAC project - $\mathrm{n}^{\circ} 202050$ - 2016-2018, extended until 2019).

\section{Authors' contributions}

Jean-Noël Ferrié wrote the first version of the article.

All authors participated in the data collection, analysis, review, and modification of the first version

Acknowledgements

We thank the patients and their families, who participated in the survey, the doctors and nurses who answered our questions and helped us, the IRC who constantly supported our work. 


\section{References}

1. James CD, Hanson K, McPake B, Balabanova D, Gwatkin D, et al. To retain or remove user fees?: Reflections on the current debate in low- and middle-income countries. Applied Health Economics \& Health Policy. 2006;5(3):137-153. https://doi.org/10.2165/00148365-200605030-00001.

2. Yates R. Universal Health Care and Removal of Users Fees. The Lancet. 2009;373(9680):2078-2081. https://doi.org/10.1016/S0140-6736(09)60258-0.

3. Nguyen HT, Torbica A, Brenner S, Kiendrébéogo JA, Tapsoba L, Ridde V, De Allegri M. Economic Evaluation of User-Fee Exemption Policies for Maternal Healthcare in Burkina Faso: Evidence From a Cost-Effectiveness Analysis. Value Health. 2020;23(3):300-308. https://doi.org/10.1016/j.jval.2019.10.007.

4. Brunet-Jailly J. Gratuité des soins ? Ce qu'il faudrait prouver.... Afrique contemporaine. 2018;265(1):123-139.

5. Olivier de Sardan J.-P, Ridde V. Réponse au texte « Gratuité des soins ? Ce qu'il faudrait prouver... » de Joseph Brunet-Jailly. Afrique contemporaine. 2018;265:141-152. https://doi.org/10.3917/afco.265.0141.

6. Olivier de Sardan J-P, Ridde V. L'exemption de paiement des soins au Burkina Faso, Mali et Niger. Les contradictions des politiques publiques. Afrique contemporaine. 2012;3(243):11-32. https://doi.org/10.3917/afco.243.0011.

7. Robert E, Samb O.M, et al. Building a middle-range theory of free public healthcare seeking in subSaharan Africa: a realist review. Health Policy and Planning. 2017;32(7):1002-1014. https://doi.org/10.1093/heapol/czx035.

8. Gilson L. The Lessons of User Fee Experience in Africa. Health Policy and Planning. 1997;12(3):273285.

9. Pierson P. When Effect Becomes Cause: Policy Feedback and Political Change. World Politics. 1993; 45(4):595-628.

10. Weaver K. The Politics of Blame Avoidance. Journal of Public Policy. 1986;6(4):371-398. https://doi.org/10.1017/S0143814X00004219.

11. Mladovsky Ph, Ba, M. Removing user fees for health services: A multi-epistemological perspective on access inequities in Senegal. Social Sciences and Medecine. 2017;188:91-99. https://doi.org/10.1016/j.socscimed.2017.07.002

12. Ferrié J.-N, Omary Z. La trappe des décisions irréfléchies : le Régime d'assistance médicale au Maroc (RAMed) et le Plan Sésame au Sénégal. Mondes en développement. 2019;187(3):15-28. https://doi.org/10.3917/med.187.0015.

13. Ganle J.K, Parker M, Fitzpatrick R, Otupiri E. Inequities in accessibility to and utilisation of maternal health services in Ghana after user-fee exemption: a descriptive study. International Journal for Equity in Health. 2014;13(89). https://doi.org/10.1186/s12939-014-0089-z. 
14. Ferrié J.-N. Entering the "Virtuous Circle": The Strength of Democratic Designs in Egypt and Morocco. In: Kienle E. (ed.), Politics from Above, Politics from Below: The Middle East in the Age of Economic Liberalization. London, Saqi Books. 2003.

15. National Health Insurance Agency. Activity report of the National Health Insurance Agency (ANAM). Rabat: ANAM; 2016.

16. Cottin R. Le ciblage direct des ménages est-il possible pour les politiques de santé ? Le cas du RAMed au Maroc. Mondes en développement. 2018;187(3):29-50. https://doi.org/10.3917/med.187.0029.

17. Ministry of Health. Sectoral Strategy of the Ministry of Health 2012-2016. Rabat: Ministry of Health; 2012.

18. Ferrié J.-N, Omary Z, Serhan O. Le Régime d'assistance médicale (RAMed) au Maroc : les mécomptes du volontarisme et de l'opportunisme. Revue Française des Affaires Sociales. 2018;1:125-143. https://doi.org/10.3917/rfas.181.0125.

19. Ababou M, Benkirane W. La persistance des inégalités dans un dispositif de lutte contre les inégalités médicales : l'accès aux soins d'oncologie à Fès et à Meknès. Mondes en développement. 2019;187(3):85-96. https://doi.org/10.3917/med.187.0085.

20. Jouilil Y, Lechheb H, Ouakil H. Health Insurance for The Poor : Impact Assessment of Morocco's RAMed Plan on Healthcare Consumption Using. A Household Panel Survey Data. European Journal of Economics and Financial Research. 2019;3(4):58-69. http://doi.org/10.5281/zenodo.3347199.

21. Zammar R, Abdelbaki N. Project evaluation (RAMED). Case of dialysis care in the Sous Massa region. Journal of Economics, Management, Environment and Law. 2019;2(3):92-101.

22. Mettler S, Soss J. The Consequences of Public Policy for Democratic Citizenship : Bridging Policy Studies and Mass Politics, Perspectives on politics. 2004;2(1):55-73. https://doi.org/10.1017/S1537592704000623.

23. Revillard A. Saisir les conséquences d'une politique à partir de ses ressortissants. La réception de l'action publique. 2018;68(3):469-491. https://doi.org/10.3917/rfsp.683.0469.

24. Gruénais M.-E. Du 'bon usage' des ambulances : enjeux économiques, identitaires et de gouvernance locale en Afrique. Horizons sociologiques. 2015;1:171-183.

25. Bekkali, R. Lutte contre le cancer au Maroc: L'apport de la Fondation Lalla Salma. International Journal of Medecine and Surgery. 2017;4(s):55-59. DOI: 10.15342/ijms.v4is.142

26. Blundo G. Une administration à deux vitesses Projets de développement et construction de l'État au Sahel. Cahiers d'études africaines. 2011;202-203:427-452. https://doi.org/10.4000/etudesafricaines.16716

27. Maluka S.O. Why are pro-poor exemption policies in Tanzania better implemented in some districts than in others ?. International Journal for Equity in Health. 2013;12(80). https://doi.org/10.1186/1475-9276-12-80.

28. Omori S, Alagon M. Polycentric governance and the provision of free healthcare services at public hospitals in the Philippines. Health Policy Plan. 2020;35(8):983-992. 
https://doi.org/10.1093/heapol/czaa053.

29. Benbakhta, B, Tazi, M, Benjaafar, N, Khattabi, A et Maaroufi, A. Déterminants des délais patient et système de santé des femmes atteintes d'un cancer du sein au Maroc. Revue d'Épidémiologie et de Santé Publique. 2013;63(3): 191-201. https://doi.org/10.1016/j.respe.2015.03.121 